\title{
Saudi Women and the Expression of Identity in the Domestic Living Space
}

\author{
Raghda Hassan Hareri \\ Department of Interior Design, Edinburgh College of Art, University of Edinburgh, Edinburgh, UK \\ Email address: \\ Raghdh.h@gmail.com
}

To cite this article:

Raghda Hassan Hareri. Saudi Women and the Expression of Identity in the Domestic Living Space. Humanities and Social Sciences. Vol. 6, No. 1, 2018, pp. 7-11. doi: 10.11648/j.hss.20180601.12

Received: November 1, 2017; Accepted: December 8, 2018; Published: March 5, 2018

\begin{abstract}
This paper entails a non-western analysis of the contemporary home environment. The main focus of this study is the role of women in family living room design, particularly in the context of Jeddah city, Saudi Arabia. The purpose of this study was to determine how the interior design of domestic space offers opportunities for women to present their identity. Saudi women using their living space within the home can play a role in expressing the identity of those women through the experience of designing this space and the interaction with its objects. The methodological framework has been structured into an ethnographical approach, which involved in-depth interviews with middle class housewives in their living rooms, aimed to seek information about experiences, interaction and values in the home environment, and enables identity presentation in the family living room. In addition, associated methods, such as photographic and video records, coding the living space features and visual observation of the living room were used to enrich data collection and unpack the environmental meaning. These mixed methods helped to understand the reality of women's life experiences and provide a compelling portrait of women's roles and identity within their living space. This paper explains the expression of individual (women) identity and the expression of group (family) identity within the living rooms. The living room in Jeddah homes is the centre space of symbolic interaction, where "I" meets "them", where women show how well they have presented themselves and the values of their families in the living room context.
\end{abstract}

Keywords: Domestic Environment, Living Space, Women, Family, Identity

\section{The Research Context}

Material culture can therefore be understood in terms of the physical space, such as the domestic space. The term 'space' represents "the physical container of activities and objects, 'place' is a particular portion of space that meets physiological and psychological needs of people while evoking meaningful and memorable messages of a specific culture" [1]. This understanding informs the aim of this paper which is to explore how the interior design of the domestic living space articulates the women identity in the context of Saudi culture.

The home environment and identity have long been a topic of interest by Saudi Architects. A study by Al-Naim showed how the house in Hofuf could be seen as an expression of individual identity. The women, for example, require a social domain (women's majlis) that maintains their identity. This is an expression of the role of women in house design. He suggests that this is an indication of the changing status of women and how they have developed their own domain [2]. The architect Alaa Al-Ban in her research on architecture and cultural identity in the traditional homes of Jeddah, examined the making of the traditional Hijazi residences and revealed how the built forms are based upon women needs and interests [3]. My proposed research therefore investigates the effect of living space furnishing and decorating on women's role and identity in their home environment. The purpose of studying women's identity within the home environment concerns the fact that identity has become an important social and cultural issue in Saudi Arabia.

\section{Identity in the Home Environment}

A shared view in the literature on identity is that one's identity is what makes a person unique, different, and distinguished from others. What differs in these accounts is 
what factors are involved in making one unique, with two main strands emerging: identity as the distinguishing "characteristics, feelings or beliefs"[4], or identity as the distinguishing "qualities and attitudes" that a person or group of people have [5]. In general, the purpose of this paper is not to structure a definition of identity, but to explore the concept of identity as a personal and physical connotation, by understanding how identity is structured in the home environment through interaction between residents and their surrounding physical objects. Identity, according to this view, can be seen as a way of identifying persons or groups through a collective set of characteristics or attitudes that differentiate person and group from others within the home environment.

In the home environment, Al-Naim states that "the concept of identity should be seen from three main aspects: physical aspects where the perceptual communications are manifested through objects which people make and use, social aspects by which people produce and mobilise meanings, and finally temporal aspects where the meanings of things continue in individual and collective memories" [2]. The argument that Al-Naim introduces here is very interesting to follow in this paper by considering the three aspects of identity. This leads to two new questions: First, is there any specific way to create an identity in the home environment? Second, how do residents present their identities within their home spaces?

Residents can express identity in the home environment. According to Blunt "Whether as a concept or a physical place, 'home' is a highly fluid and contested site of human existence that reflects and reifies identities and values" [6]. The home environment is one way that people tend to distinguish themselves from others and express their identity, and so, in relation to this context, Saudi residents' interior design can (quite literally) speak words, present meanings and address the identity of its inhabitants. Al-Naim considers home design to be a gradual interactive process between residents and the physical environment. Over the time of residence, people tend to express their identity in their houses [2]. Akbar supports the view of Al-Naim that the function of decorative objects is not limited to visual comfort and structural and decorative articulation, but rather goes beyond this point to deal with psychological aspects such as identity [7]. In this section, I investigate how domestic spaces and furniture become a major vehicle for displaying identity. Based on this general consensus, Al-Nafea states that identity could be presented by furnishing and use of space: "the arrangement and use of space can be considered a rich symbolic system through which individuals and social groups project their own identities in differing degrees and ways" [8].

Mahmud asserts that the place takes its identity from the resident and the resident takes his identity from the place, using the work of Proshansky, Fabian, and Kaminoff to explain the components of identity. In their paper PlaceIdentity: Physical World Socialisation of the Self, they note that "People's place attachment goes directly with space interaction in any residential area of an individual, while identity refers to memories, ideas, feelings, attitudes, values, preferences, meanings and conceptions of behavior and experience which relate to the variety and complexity of physical setting that defines existence of every human being" [9]. Identity can be expressed in the home environment by the inhabitants, who have the ability to create certain combinations of physical, social, cultural, and psychological aspects through their interaction with the surrounding physical objects in the domestic space. We can argue that individuals are therefore creators of both identity and spaces.

Home is the place where individual identities can be formed. In this section, we need to discover more about how Saudi women personalize their space within their homes. As the anthropologist Daniel Miller states, images of lifestyles are attached to objects, serving as a pivot around which identities are constructed [10]. Furthermore, Al-Naim states that individual identity could be seen "in terms of role, such as me vs. others" [2]. Philosopher Aviezer Tucker also suggests that "home may be an expression of a person's subjectivity in the world. Alternatively, he states that it may simply be a space where people feel at ease and are able to express and fulfil their unique selves or identities" [11]. The questions that come to the researcher's mind are whether Saudi women, as individuals, communicate with the society through their home design? What are the mechanisms these women use to present their identities?

\section{Methodology Framework}

An ethnographic approach has been employed in this research, which involves in-depth interviews with middle class housewives, aims to seek information about behavior, experiences, and values in the home environment, and discusses identity presentation in the living space. In addition, associated methods are used, such as the creation of photographic and video records, coding the living space features for identity cues and visual observation of the living room.

In-depth interviews have been used to collect data about women's behavior in their homes. My sample involved women (the female heads) living with their families from the middle class. The housewives were of various age groups and educational levels. This selection allows the researcher to investigate the women's experience in a variety of contexts, to present their effective roles within the family and home. During the interviews with participants, attention was paid to the self and others: parties are created and defined by using the words "I" and "we" during participants' answers. These words are used as cues to identify and distinguish the women from their families, and can be seen as a starting point in investigating their respective identities.

Each participant was asked to describe how she and her family live their daily lives within the living space. This was done with a small digital video camera (Sony PJ410) for approximately 10-15 minutes, detailing the interior design of the living space, on a tour led by the female participants. The participants conveyed their thoughts about the significant aspects of their living space in rich, personal words, illustrating how women really feel about their home living spaces. 
A model has been developed by the psychologists Samuel Gosling, Kenneth Craik, Nicholas Martin, and Michelle Pryor, who introduced The Personal Living Space Cue Inventory (PLSCI), which is designed to document features of personal living spaces (PLSs). This approach treats every item within a space as a possible physical residue of the prior behaviour of the individual who occupies that space [12]. The living spaces were observed to express individual design interests, such as types of furniture and decorative elements within the living spaces, in order to find out how these elements have been used as symbols to express the residents' identity. Indeed, this observation of living space contents is non-resident observation. This mechanism is used to unpack the environmental meanings through a process of treating the content (furnishing and decorating) of living spaces as possible physical residue of the trends exhibited by the residents' identity.

\section{The Expression of Family Identity in the Living Space}

Home is understood as an interwoven identity through the woman's projection of self and the family members' projection of group identity. The family members in the Jeddah home environment build their internal relationships within the living space. Through the analysis of the interview data contents, it is important at this stage to address some of the familial values expressed by the housewives. The collective values that have played an essential role in the formation of collective identity for the family within their contemporary living space in Jeddah are centred on family beliefs, marriage relationships, plans and events, achievements, extended family relationships, kinship groups and tradition.

Two participants reported that using the largest space in their villa as a living room supports the value of family gathering, because family members can meet together in this room and share their time and activities together. In another living room, the arrangement of the seating furniture allowed the family to be as close as possible, to encourage family interaction. The valuing of a warm place for the family can be seen to be met in the living room's colour scheme, see Figure 1.

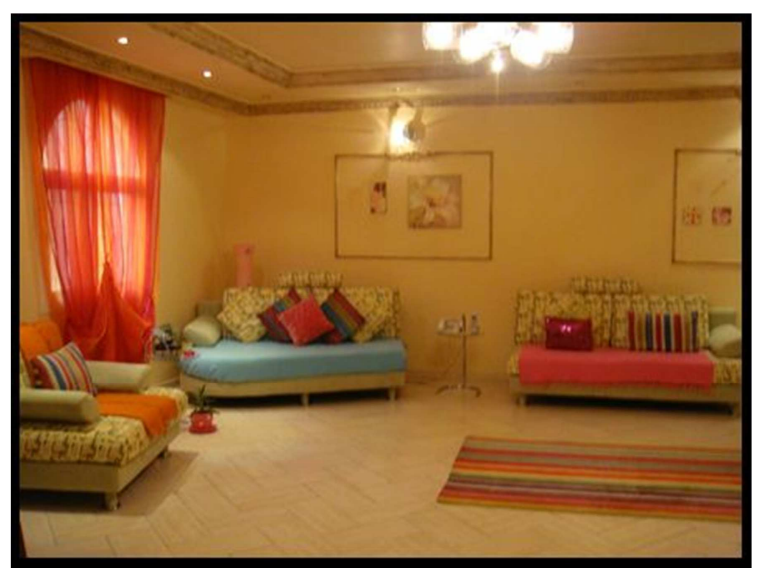

Source: Fieldwork in Jeddah, 2015

Figure 1. The arrangement of furniture and its colour in one living room.
One participant had created the living space for family enjoyment and leisure time activities, and also went beyond this to display the positive times they had had in the room which indicated the family's identity. Another participant declared that family gathering was the first value in the living room, along with sharing and doing things together. She reported using this central space in their villa as a living room to support the value of family gathering:

I use this central space as a living space to support the values of family gatherings, such that family members can meet together in this room and share their time and activities together, such as: drawing, reading, art working and finding about new things in addition to watching television.

One participant mentioned that her family values were presented in their living room as a space to share all the family activities, such as watching television and eating, so these activities forbidden in their private rooms, to allow family interaction and to strengthen their values (such as respect, affection, love and intimacy) through their communication in their living room.

The meaning of home in this paper is shown by experiencing the Jeddah living room as shared space for women and their families - through activities and values - to reflect a sense of belonging and identity. Family identity can be understood as the production of common behaviour in the system of space use that is exchanged and shared among family members. Family context allows for a closer examination of the specific ways in which the intersections between woman and family are produced. This aspect is important in two ways. Firstly, it allows for an examination of how family life may affect the accommodation of the woman (a future area for study). Secondly, which is the main focus of this paper, it allows for an examination of how women's perspectives and desires may affect the whole family's functioning within the living space. In this research context, the living room is designed by housewives but it is a shared place in which family values work to present a joint family identity. It is a practical combination, in terms of group behaviour and an individual symbolic component, that fosters identity and meaning-making in a shared place. This paper serves to illustrate both the individual women's sense of belonging with family members (joint identity) and their own sense of who they are (individual identity). This is positively represented in the context of the living room, through highlighting the intersection between the woman's individual roles and desires and family values.

\section{The Expression of Women's Identity in the Living Space}

Although many research studies have established that the home is a place of self-expression, the individualised concept of self as assumed in western literature is not a universal given, as in other societies the self is much more socially situated. In the context of the Saudi home environment, the process by which women present who they are through the 
design of their family home spaces is explored in this section. In a family, no one has power without the presence of others [13]. Identity is the kind of projection that one makes in social interaction with others. The interesting question at the present time is: who plays the instrumental and expressive roles in the Saudi family? Saudi women are active agents who design their homes and are capable of turning the living room into valued social space; as Silva argues, "women are active agents who through careful consumption are capable of taking the family into a more valued social space" [14]. One participant declared that her living room was a place for her, her family and her grandchildren. In presenting her design work, so it was presenting her identity. She said, "The living room represents me, as this is my design work and it represents my family, as it is a place for me and family members to gather." It gave her a sense of personal location, but it was also about her social relationships and the complex involvement with family members and visitors.

In Saudi culture, the family is the basis of social construction, as women cannot live alone in their private homes after a certain age or after divorce, so their identity is defined in familial terms and relationships. The living room in the Jeddah home is the central ring of symbolic interaction where 'I' meets 'them', where women show how well they have expressed the subjectivity of themselves and the values of their families. There is a link between the goal of family togetherness, and the goal of self-achievement. Saudi women are not to be confined to a familial role only, as the growing movement in society is that women should have a public persona, which repositions them within the family household and the wider social world.

We can see the relationship between domesticity and femininity that casts the role of women as the creators of domestic interiors, through tasteful furnishings, decorative objects and arrangement. In this case, while the women saw themselves as responsible for maintaining the household in practical and aesthetic terms, their identity appears within this context. Data collected from the housewives constitute the first source of such support. The majority of housewives reported that their living rooms presented their identity 'very well' in the family layout. Participants declared that their living room represented them but also a place for their family gathering. One participant declared "The living room represents me more than my family with regard to the room design, as these are my favourite colours and my fabric choice, but the room layout and furniture arrangement is designed to provide a space for family use." Another participant added "The living room represents me, as this is my design work, my art work and my book collection. Also, it represents my family as it is a place for me and my family members gathering."

The personal collections of objects, the desired way of decorating and arranging domestic living rooms and space experiences present a woman's identity. A "gendered space" is reflected in symbols that are used in specific spaces, by manipulating the meaning of space [15]. Identity is shaped by the interaction between the woman and the surrounding physical interiors in the living place. Both Mahmud and AlNaim agree that, from a Saudi context, identity is something that is formed from the interaction between individuals and the surrounding physical objects [9] and [16].

The decorative objects and furniture in these living spaces materialize the women's identities. One participant declared that her living room represents her very well, and spoke of a love for flowers, as there are floral patterns and flower arrangements everywhere in the living room (see Figure 2 below). She also mentioned that "everyone who enters my living room says this really is your space-even my clothes are always pink and have a similar floral pattern". The living room reflects her personal footprint, as it is designed using her favourite colours and patterns.

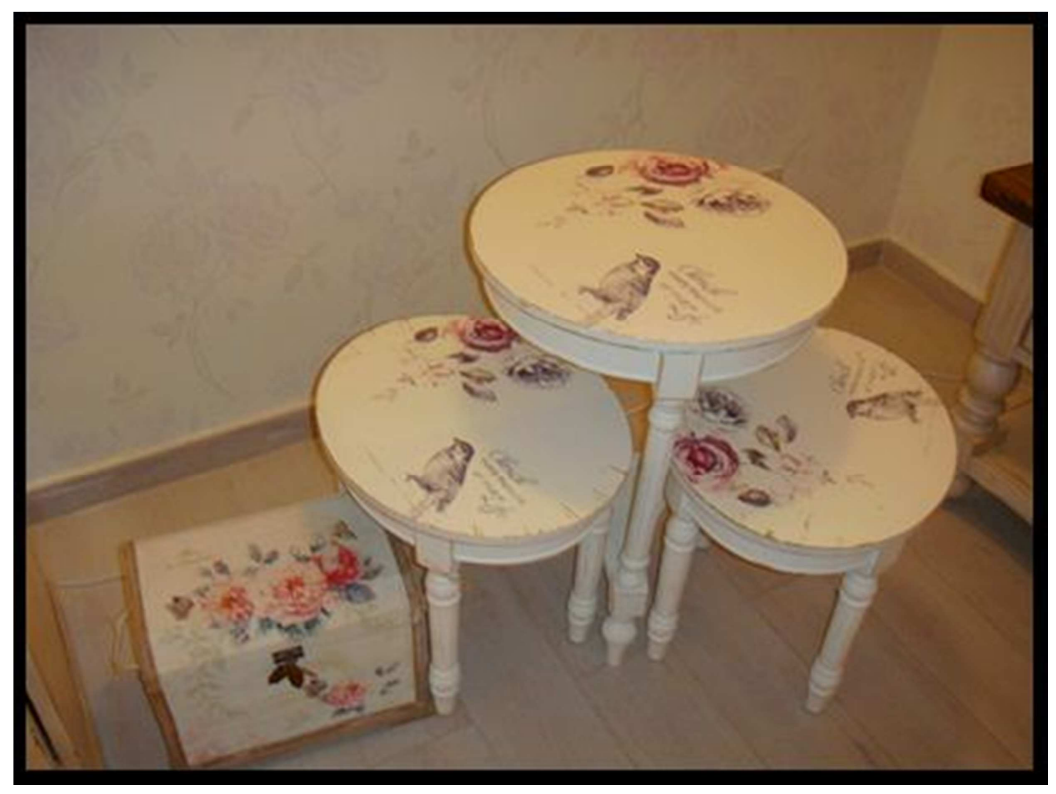

Source: Fieldwork in Jeddah, 2015

Figure 2. Example of floral pattern in one living room. 
Another participant's personal footprint is indicated by the historical forms of interest by choosing furnishings and decorating with a mixture of fragments of antiquity. Two participants explicitly expressed that the living room showed off their personal footprint, by displaying their artwork and handiwork, such as the paintings which hung on the living space wall, as a personal footprint for those women. In the form of specialised (as an artist) or handwork projects and personalised objects held by the housewife and used to furnished the living space, which confers on its holder a constant value. These homes became material manifestations of the women's personal identities [17].

One cannot assume that all women experience and exercise power in similar ways. Saeed Hamdan, who studied social change in the Saudi family, describes the joint decision between couples in young families in different contexts, for example in buying a house or furniture [18]. On the other hand, Al-Nafea holds that there is a competition between men and women to shape the domestic interiors and express their identities [8]. There was no competition between the Jeddah family members under study in furnishing and decoration their living rooms, as women were the powerful members. This can be attested by the living rooms being used to present the image of female identity. Some cases show joint decisions between the wife and husband, rather than competition between the two. In this paper it is argued that Saudi women in Jeddah nowadays have more power and a greater role in the home than men: they care about the expression of their identities and putting their stamp and personal footprint on the home environment.

\section{The Research Summary}

In this paper, as the woman imposed her power in designing the living space, so it is an imposed environment for her family members, but still a shared place to use, in which the family values work to present a joint family identity. The individual perspective of the housewife does not affect the family's functioning in the space, but, on the other hand, the housewife views herself as linked to her family. It is a practical combination in terms of group behavior and an individual symbolic component that fosters identity and meaning-making in a shared place. This paper explains the expression of individual (women) identity and the expression of group (family) identity within the living rooms. The living room in Jeddah homes is the centre space of symbolic interaction, where "I" meets "them", where women show how well they have presented themselves and the values of their families in the living room context. There is a link between the goal of family togetherness, and the goal of self-achievement. Saudi women are not to be confined to a familial role only, as the growing movement in society gives women a public persona, repositioning them within the family household and the wider social world.

\section{References}

[1] Al-Kodmany, K. \& M. Ali, M. (2012) Skyscrapers and Placemaking: Supporting Local Culture and Identity, ArchnetIJAR, International Journal of Architectural Research, 6 (2), 43-64.

[2] Al-Naim, M. (1998) Continuity and Change of Identity in The Home Environment: Development of the private house in Hofuf: Saudi Arabia, Thesis (PhD), University of Newcastle upon Tyne.

[3] Al-Ban, A. (2016). Architecture and Cultural Identity in the Traditional Homes of Jeddah, Unpublished Thesis (PhD), University of Colorado.

[4] Oxford Advanced Learner's Dictionary (2000), Sixth edition, Oxford: Oxford university Press.

[5] Longman (2009) Dictionary of Contemporary English for Advanced Learners, Person Education Limited.

[6] Blunt, A. (2005) Cultural geography: Cultural geographies of home. Progress in Human Geography, 29 (4), 505-515.

[7] Akbar, S. (1998) Home and Furniture: Use and Meaning of Domestic Space, Jeddah, Saudi Arabia, Thesis (PhD), University of Newcastle upon Tyne.

[8] AL-Nafea, N. A. (2006) Home Environment in Transition: Women and Design in the City of Riyadh, Saudi Arabia. Thesis (PhD), London South Bank University.

[9] Mahmud, S. (2007) Identity Crisis due to Transformation of Home Environment: The Case for Two Muslim Cities, Dhaka and Hofuf. METU JFA, 24 (2), 37-56.

[10] Miller, D. (1987) Material Culture and Mass Consumerism. New York: John Wiley \& Sons, Inc.

[11] Mallett, S. (2004) Understanding home: A critical review of the literature, Sociological Review, 52 (1), 62-89.

[12] Gosling, S., Craik, K. H., Martin, N. R. \& Pryor, M. R., (2005) The Personal Living Space Cue Inventory: An Analysis and Evaluation. Environment and Behavior, 37 (5), 683- 705.

[13] Galvin, K. M., Braithwaite, O. D. \& Bylund, L. C. (2015) Family Communication: Cohesion and Change, $\left(9^{\text {th }}\right.$ Edition). Taylor and Francis.

[14] Silva, E. B., (2000) The Politics of Consumption at Home: Practices and Dispositions in the Uses of Technologies, Pavis Papers in social and cultural research No. 1, Milton Keynes: Open University Press.

[15] Hamdan-Saliba, H. and Fenster, T. (2012) Tactics and strategies of power: the construction of spaces of belonging for Palestinian women in Jaffa-Tel Aviv, Women's Studies International Forum, 35, 203-213.

[16] Al-Naim M. (2008) Identity in Transitional Context: OpenEnded, International Journal of Architectural Research, 2 (2), 125-146.

[17] McKellar, S., Sparke, P., Victoria Albert Museum, \& Royal College of Art. (2004). Interior design and identity. Manchester: Manchester University Press.

[18] Hamdan, S. (1990) Social Change in the Saudi Family, Thesis $(\mathrm{PhD})$, Iowa State University. 